\title{
Lumbo-peritoneal shunting for idiopathic intracranial hypertension: what is the optimum catheter length and placement to avoid low-pressure headaches? Roger Strachan*, Desederio Rodrigues and Savithru Prakash
}

Address: Department of Neurosurgery, The James Cook University Hospital, Marton Road, Middlesbrough, TS4 3BW UK

Email: Roger Strachan* - rogerstrachan@hotmail.com

* Corresponding author

from 50th Annual Meeting of the Society for Research into Hydrocephalus and Spina Bifida

Cambridge, UK. 30 August - 2 September 2006

Published: 2I December 2006

Cerebrospinal Fluid Research 2006, 3(SuppI I):S27 doi:I0.II86/I743-8454-3-SI-S27

(C) 2006 Strachan et al; licensee BioMed Central Ltd.

\section{Background}

Lumbo-peritoneal shunting is a standard treatment for Idiopathic ("Benign") Intracranial Hypertension. Despite the routine nature of the procedure, complications are common, particularly the problem of over-drainage leading to low-pressure symptoms. We have audited the senior author's results over the last ten years to identify the extent of the problem, and designed a simple bench-testing of catheters of different lengths, draining at different pressure heads and with different vertical drops, in an attempt to ascertain the optimum catheter placement and length that might reduce the occurrence of low pressure headaches.

\section{Materials and methods}

There were two arms to the project. The first was a retrospective case-notes clinical audit of complications from lumbo-peritoneal shunts inserted by the senior author over the last 10 years. The second was the design, construction and application of a simple bench experiment to ascertain the flow rates through catheters of three different lengths $(60,83$ and $100 \mathrm{cms})$, at three different pressure heads $\left(15,25\right.$, and $35 \mathrm{cms} \mathrm{H}_{2} \mathrm{O}$ - to simulate 3 different placements in the lumbar theca), and three different vertical drops $(10,20$ and $30 \mathrm{cms}$ - to simulate the possible effect of siphoning)

\section{Results}

Complication rates from LP shunts are high, but rarely serious. One of the most common is over-drainage. The incidence of idiopathic intracranial hypertension is rising, perhaps related to a significance rise in the incidence of obesity. The flow rate through the catheters is dependent on many variables including catheter length, the pressure head at the proximal end, and the vertical drop of the distal end. Our results indicate that the most significant factor of these three is catheter length, but the pressure head and vertical drop can still affect flow rates by over $50 \%$.

\section{Conclusion}

The incidence of IIH is rising, and the need for LP shunting will increase. Catheter length and placement are important in reducing the risk of low pressure symptoms, but further research and development is required to design innovative ways of over-coming problems related to LP shunting, particularly the problems with over-shunting. 